\title{
Prevalence of hyposmia and hypogeusia in 390 COVID-19 hospitalized patients and outpatients: a cross-sectional study
}

\author{
Agathe Nouchi $^{1,2}$ (1) Julie Chastang ${ }^{3,4} \cdot$ Makoto Miyara $^{5} \cdot$ Julie Lejeune $^{6} \cdot$ André Soares $^{3} \cdot$ Gladys Ibanez $^{3,4}$. \\ David Saadoun ${ }^{7}$. Capucine Morélot-Panzini ${ }^{8} \cdot$ Thomas Similowski $^{8} \cdot$ Zahir Amoura $^{9}$ • Jacques Boddaert ${ }^{1,5,10}$. \\ Eric Caumes $^{1,2,4}$ - Alexandre Bleibtreu ${ }^{1,2}$ - Alain Lorenzo $^{3}$. Florence Tubach ${ }^{6}$ • Valérie Pourcher ${ }^{1,2,4}$
}

Received: 5 June 2020 / Accepted: 30 September 2020 / Published online: 8 October 2020

(C) Springer-Verlag GmbH Germany, part of Springer Nature 2020

\begin{abstract}
Anecdotal evidence rapidly accumulated during March 2020 from sites around the world that sudden hyposmia and hypogeusia are significant symptoms associated with the SARS-CoV-2 pandemic. Our objective was to describe the prevalence of hyposmia and hypogeusia and compare it in hospitalized and non-hospitalized COVID-19 patients to evaluate an association of these symptoms with disease severity. We performed a cross-sectional survey during 5 consecutive days in March 2020, within a tertiary referral center, associated outpatient clinic, and two primary care outpatient facilities in Paris. All SARS-CoV-2-positive patients hospitalized during the study period and able to be interviewed $(n=198)$, hospital outpatients seen during the previous month $(n=129)$, and all COVID-19-highly suspect patients in two primary health centers $(n=63)$ were included. Hospitalized patients were significantly more often male (64 vs $40 \%$ ) and older (66 vs 43 years old in median) and had significantly more comorbidities than outpatients. Hyposmia and hypogeusia were reported by $33 \%$ of patients and occurred significantly less frequently in hospitalized patients (12\% and $13 \%$, respectively) than in the health centers' outpatients (33\% and $43 \%$, respectively) and in the hospital outpatients (65\% and $60 \%$, respectively). Hyposmia and hypogeusia appeared more frequently after other COVID-19 symptoms. Patients with hyposmia and/or hypogeusia were significantly younger and had significantly less respiratory severity criteria than patients without these symptoms. Olfactory and gustatory dysfunction occurs frequently in COVID-19, especially in young, non-severe patients. These symptoms might be a useful tool for initial diagnostic work-up in patients with suspected COVID-19.
\end{abstract}

Keywords COVID-19 $\cdot$ SARS-CoV-2 $\cdot$ Hyposmia $\cdot$ Hypogeusia $\cdot$ Neurovirulence

Florence Tubach and Valérie Pourcher contributed equally to this work.

Agathe Nouchi

agathe.nouchi@aphp.fr

1 Groupe Hospitalier Universitaire APHP, Sorbonne Université, site Pitié-Salpêtrière, Paris, France

2 Département des Maladies Infectieuses et Tropicales, Groupe Hospitalier Universitaire APHP, Sorbonne Université, Hôpital Pitié-Salpêtrière, Paris, France

3 Département de Médecine Générale, Sorbonne Université, Paris, France

4 INSERM, Institut Pierre Louis d'Épidémiologie et de Santé Publique, Groupe Hospitalier Universitaire APHP, Sorbonne Université, site Pitié-Salpêtrière, Paris, France

5 INSERM UMR-S 1135, Centre d'Immunologie et des Maladies Infectieuses (CIMI-Paris), Département d'Immunologie, Groupe Hospitalier Universitaire APHP, Sorbonne Université, site Pitié-Salpêtrière, Paris, France
6 INSERM UMR-S-1136, Institut Pierre Louis d'Epidémiologie et de Santé Publique, Département de Santé Publique, Unité de Recherche Clinique Pitié, CIC-1422, Groupe Hospitalier Universitaire APHP, Sorbonne Université, site Pitié-Salpêtrière, Paris, France

7 INSERM, UMR-S-959, Immunology-ImmunopathologyImmunotherapy (I3), Department of Internal Medicine and Clinical Immunology, Groupe Hospitalier Universitaire APHP, Sorbonne Université, site Pitié-Salpêtrière, Paris, France

8 INSERM, UMR-S-1158, Service de Pneumologie et Réanimation Médicale (Département R3S), Groupe Hospitalier Universitaire APHP, Sorbonne Université, site Pitié-Salpêtrière, Paris, France

9 Inserm UMR-S 1135, Centre d'Immunologie et des Maladies Infectieuses (CIMI-Paris), Service de Médecine Interne 2, Groupe Hospitalier Universitaire APHP, Sorbonne-Université, site Pitié-Salpêtrière, Paris, France

10 Service de Gériatrie, Groupe Hospitalier Universitaire APHP, Sorbonne Université, Hôpital Pitié-Salpêtrière, Paris, France 


\section{Introduction}

The most frequent symptoms of coronavirus disease 2019 (COVID-19) are fever, dry cough, fatigue, arthromyalgia, and headache, but in March 2020, during the severe acute respiratory syndrome coronavirus 2 (SARS-CoV-2) pandemic, anecdotal evidence rapidly accumulated from sites around the world that sudden loss of smell (hyposmia) and/or taste (hypogeusia) was also occurring in COVID-19 patients, often without concomitant nasopharyngeal symptoms $[1,2]$. In a joint briefing paper by the presidents of the British Rhinological Society and of the UK ear, nose, and throat (ENT) group, loss of sense of smell was said to be a marker of COVID-19 infection and a potential screening tool to help identify otherwise asymptomatic patients [3]. After the publication of several studies reporting hyposmia and hypogeusia as frequent symptoms of COVID-19 [4, 5], the World Health Organization (WHO) included these symptoms in case definition. It has been suggested that these symptoms are related to a neuroinvasion and could be associated with severe forms of COVID-19 [6]. However, no study has focused yet on the difference of prevalence of these symptoms in COVID-19 hospitalized and non-hospitalized patients to investigate the association with disease severity.

Therefore, the aim of our study was to describe olfactory and taste disorder prevalence and compare it between hospitalized and primary care or hospital outpatients with COVID19 , to evaluate an association of these disorders with disease severity.

\section{Methods}

\section{Study design and participants}

This cross-sectional study was conducted during 5 consecutive days from March 23 to 27, 2020, in three adult COVID19 patient groups, aged 18 or over. The first group was inpatients cared for in either the infectious and tropical disease, internal medicine, pneumology, or geriatrics department within La Pitié-Salpêtrière Hospital, Paris, France. The second group were patients who had attended the infectious and tropical disease outpatient clinic, also at the same hospital, 1 month prior to and were reachable over phone during the study period. The third group attended one of two primary outpatient clinics near Paris. All inpatients and outpatients who were consulted at the hospital had confirmed positive SARSCoV-2 result using real-time reverse transcriptase polymerase chain reaction (RT-PCR) acquired from a respiratory sample (nasopharyngeal swab or induced sputum specimen). For patients seen in primary care, COVID-19 diagnosis was strongly suspected according to the treating general practitioner's clinical judgment and available data on COVID-19 infection.
Patients with mild symptoms were not being tested at that time in France.

\section{Data collection}

A medical physician interviewed inpatients and phoned outpatients consulted in the infectious diseases clinic. For the primary care outpatients, the treating general practitioner collected the data during the consultation.

Patients who were fit to be interviewed were asked if they had experienced olfactory alteration (hyposmia), taste alteration (hypogeusia), and other symptoms (asthenia, fever, cough, dyspnea, headache, rhinorrhea, nasal obstruction, diarrhea, vomiting, neurological manifestations). The disease onset date, defined as the day when the first symptom of COVID-19 was noticed, was asked to record the time from onset to interview. Symptom persistence, as well as demographic characteristics and comorbidities (hypertension, diabetes, obesity, bronchopathy, cardiopathy, nephropathy, neurologic diseases, cancer, hemopathy, and other immunosuppression), were also asked.

The research protocol was reviewed and approved by the Ethics Committee of the Sorbonne University (CER-SU) under the Institutional Review Board $N^{\circ}$ 2020-CER-2020-8. According to French law (n ${ }^{\circ} 78-17$ of 6 January 1978 on computers, files, and liberties), this study has been registered with the CNIL (French National Agency Regulating Data Protection) and was conducted in compliance with the reference methodology 004.

\section{Statistical analysis}

A global comparison of the 3 groups of patients was performed (inpatients, hospital outpatients, and primary care outpatients). Continuous variables were reported as median (interquartile range) qualitative data were reported as numbers (percentages). Categorical variables were compared using Fisher exact tests. To compare distributions of continuous outcomes over the 3 groups, nonparametric Kruskal-Wallis were performed. When a significant difference was identified overall, pairwise Wilcoxon test or Fisher exact test was computed between groups, and corresponding $p$ values were adjusted using the Benjamini-Hochberg method to correct for the multiple comparisons undertaken.

Associations between patient characteristics and presence or absence of hyposmia and/or hypogueusia were investigated through univariate analyses and then using a multivariate logistic regression model. Candidate variables to be included in the final model were those with a univariate $p$ value $<0.05$. A stepwise backward method based on the likelihood ratio test was undertaken. Results of the final logistic model were reported as odds ratios (OR) with their corresponding 
confidence intervals at 95\% (CI 95\%). $p$ values of Wald test were also presented.

All statistical tests were two-sided, with $p$ values of 0.05 or less denoting statistical significance. All analyses were performed on the $\mathrm{R}$ version3.5.1.

\section{Results}

A total of 390 patients were included in the study, of whom 198 were hospitalized, 129 were infectious diseases clinic outpatients, and 63 were primary care outpatients. Thirtyseven hospitalized patients were excluded because they were unable to be interviewed (34 due to dementia, 2 severe psychiatric disorders, and 1 linguistic barrier). Demographics and comorbidities are shown in Table 1 . There were significantly older (median age 66 years), male (64\%) patients in the hospitalized group than in the two outpatient groups (43\% male with median age 43 years in the hospital outpatient group, $32 \%$ male with median age 42.5 years in the primary care outpatient group). Hospitalized patients also had significantly more comorbidities (Table 1).

Reports of hyposmia, hypogeusia, and other COVID-19 symptom prevalence in the 3 groups of patients are shown in Table 2. In total, 129 patients $(33 \%)$ reported hyposmia, of whom $74(19 \%)$ without nasal obstruction or rhinorrhea, 130 patients $(33 \%)$ reported hypogeusia, and 106 patients reported both $(27 \%)$. No patients reported isolated hyposmia or hypogeusia without other symptoms. There was significantly fewer reports of hyposmia (12\%) and hypogeusia (13\%) in hospital inpatients than in primary care outpatients $(33 \%$ and $43 \%$ respectively, $p<0.05)$ which was fewer again than in the hospital outpatients (65\% and $60 \%$, respectively, $p<0.05$ ). There was a significant association between hyposmia and hypogeusia $(p<0.0001)$, with $23 / 129$ (18\%) patients with hyposmia reporting no hypogeusia, and 24/130 (18.5\%) patients with hypogeusia reporting no hyposmia. Regarding the timing of hyposmia and hypogeusia onset, they appeared before ( $5 \%$ and $4 \%$, respectively), at the same time ( $46 \%$ and $36 \%$, respectively), or after (49\% and $60 \%$, respectively) the other COVID-19 symptoms. Notably, 17 patients did not remember the time of hyposmia onset and 30 patients the time of hypogeusia onset. Among the 38 patients with infection onset $>14$ days before interview and an initial hyposmia, 13 patients (34\%) still had persistent hyposmia, and 10/34 (29\%) had persistent hypogeusia.

Significantly more hospitalized patients had fever (83\%) and dyspnea (58\%) than hospital outpatients $(71 \%$ and $26 \%$, respectively) and primary care outpatients (30\% and $41 \%$, respectively), whereas inpatients reported significantly fewer headaches (16\%), nasal obstruction (4\%), and rhinorrhea (4\%) than hospital outpatients $(64 \%, 35 \%$, and $44 \%$, respectively) and primary care outpatients $(54 \%, 33 \%$, and $33 \%$, respectively) $(p<0.05)$ (Table 2). Sixty-three percent of hospitalized

Table 1 Comparison of demographics and comorbidities between hospitalized, hospital outpatients, and primary care outpatients

\begin{tabular}{|c|c|c|c|c|c|c|c|}
\hline & $\begin{array}{l}\text { Hospitalized } \\
\text { patients } \\
N=198\end{array}$ & $\begin{array}{l}\text { Hospital } \\
\text { outpatients } \\
N=129\end{array}$ & $\begin{array}{l}\text { Primary care } \\
\text { outpatients } \\
N=63\end{array}$ & $\begin{array}{l}p \text { value } \\
\text { global }\end{array}$ & $\begin{array}{l}p \text { value-adjusted } \\
\text { hospitalized pa- } \\
\text { tients } \\
\text { vs hospital outpa- } \\
\text { tients }\end{array}$ & $\begin{array}{l}p \text { value-adjusted hospitalized } \\
\text { patients vs primary care outpa- } \\
\text { tients }\end{array}$ & $\begin{array}{l}p \text { value-adjusted } \\
\text { hospital outpa- } \\
\text { tient } \\
\text { vs primary care } \\
\text { outpatients }\end{array}$ \\
\hline Age (years) & $66(55-77.6)$ & $43(32-54)$ & $42.5(33-50.8)$ & $<0.001$ & $<0.001$ & $<0.001$ & 0.832 \\
\hline Female & $72(36 \%)$ & $73(57 \%)$ & $43(68 \%)$ & $<0.001$ & 0.157 & $<0.001$ & $<0.001$ \\
\hline HTA & $80(40 \%)$ & $15(12 \%)$ & $16(25 \%)$ & $<0.001$ & $<0.001$ & 0.049 & 0.030 \\
\hline Diabetes & $52(26 \%)$ & $6(5 \%)$ & $3(5 \%)$ & $<0.001$ & $<0.001$ & $<0.001$ & 1.00 \\
\hline Obesity & $22(11 \%)$ & $9(7 \%)$ & $6(10 \%)$ & 0.476 & & & \\
\hline Bronchopathy & $33(17 \%)$ & $14(11 \%)$ & $5(8 \%)$ & 0.127 & & & \\
\hline Cardiopathy & $39(20 \%)$ & $2(2 \%)$ & $4(6 \%)$ & $<0.001$ & $<0.001$ & 0.017 & 0.092 \\
\hline Nephropathy & $19(10 \%)$ & $1(1 \%)$ & $0(0 \%)$ & $<0.001$ & 0.002 & 0.014 & 1.00 \\
\hline $\begin{array}{c}\text { Neurological } \\
\text { diseases }\end{array}$ & $26(13 \%)$ & $1(1 \%)$ & $1(2 \%)$ & $<0.001$ & $<0.0001$ & 0.011 & 0.55 \\
\hline Cancer & $23(12 \%)$ & $2(2 \%)$ & $1(2 \%)$ & $<0.001$ & 0.001 & 0.019 & 1.00 \\
\hline Hemopathy & $13(7 \%)$ & $1(1 \%)$ & $2(3 \%)$ & 0.0022 & 0.032 & 0.534 & 0.377 \\
\hline Graft & $7(4 \%)$ & $2(2 \%)$ & $0(0 \%)$ & 0.269 & & & \\
\hline $\begin{array}{l}\text { Other } \\
\text { immunosuppres- } \\
\text { sion* }\end{array}$ & $17(9 \%)$ & $4(3 \%)$ & $3(5 \%)$ & 0.106 & & & \\
\hline
\end{tabular}

${ }^{*} \mathrm{HIV}$, autoimmune disease, inflammatory disease, sickle cell anemia. Data expressed in median (IQR) for continuous variables or $N(\%)$ for qualitative data 
Table 2 Comparison of COVID-19 symptoms, hyposmia, and hypogeusia between hospitalized, hospital outpatients, and primary care outpatients

\begin{tabular}{|c|c|c|c|c|c|c|c|}
\hline & $\begin{array}{l}\text { Hospitalized } \\
\text { patients } \\
N=198\end{array}$ & $\begin{array}{l}\text { Hospital } \\
\text { outpatients } \\
N=129\end{array}$ & $\begin{array}{l}\text { Primary care } \\
\text { outpatients } \\
N=63\end{array}$ & $\begin{array}{l}p \text { value } \\
\text { global }\end{array}$ & $\begin{array}{l}p \text { value adjusted- } \\
\text { hospitalized pa- } \\
\text { tients } \\
\text { vs hospital outpa- } \\
\text { tients }\end{array}$ & $\begin{array}{l}p \text { value hospitalized } \\
\text { patients vs primary } \\
\text { care outpatients }\end{array}$ & $\begin{array}{l}p \text { value hospital } \\
\text { outpatient vs } \\
\text { primary } \\
\text { care outpatients }\end{array}$ \\
\hline $\begin{array}{l}\text { Time since onset of first } \\
\text { symptom (days) }\end{array}$ & $9(5-12)$ & $14(10-19)$ & $7(4-10)$ & $<0.001$ & $<0.001$ & 0.030 & $<0.001$ \\
\hline Asthenia & $122(62 \%)$ & $108(84 \%)$ & $35(56 \%)$ & $<0.001$ & $<0.001$ & 0.46 & $<0.001$ \\
\hline Cough & $151(76 \%)$ & $97(75 \%)$ & $51(81 \%)$ & 0.676 & & & \\
\hline Fever & $165(83 \%)$ & $92(71 \%)$ & $19(30 \%)$ & $<0.001$ & 0.013 & $<0.001$ & $<0.001$ \\
\hline Headache & $31(16 \%)$ & $83(64 \%)$ & $34(54 \%)$ & $<0.001$ & $<0.001$ & $<0.001$ & 0.208 \\
\hline Diarrhea and/or vomiting & $70(35 \%)$ & $42(33 \%)$ & $8(13 \%)$ & 0.003 & 0.635 & 0.001 & 0.004 \\
\hline Dyspnea & $115(58 \%)$ & $34(26 \%)$ & $26(41 \%)$ & $<0.001$ & $<0.001$ & 0.032 & 0.046 \\
\hline $\begin{array}{l}\text { Neurological } \\
\text { manifestations }\end{array}$ & $21(11 \%)$ & $10(8 \%)$ & $1(2 \%)$ & 0.056 & 0.44 & 0.1 & 0.156 \\
\hline Nasal obstruction & $9(5 \%)$ & $37(29 \%)$ & $18(29 \%)$ & $<0.001$ & $<0.001$ & $<0.001$ & 1.00 \\
\hline Rhinorrhea & $9(5 \%)$ & $53(41 \%)$ & $27(43 \%)$ & $<0.001$ & $<0.001$ & $<0.001$ & 0.877 \\
\hline Hyposmia & $24(12 \%)$ & $84(65 \%)$ & $21(33 \%)$ & $<0.001$ & $<0.001$ & $<0.001$ & $<0.001$ \\
\hline Persistent hyposmia & $22 / 24(92 \%)$ & $26 / 84(31 \%)$ & $19 / 21(90 \%)$ & 0.001 & $<0.0001$ & 0.225 & 0.003 \\
\hline $\begin{array}{l}\text { Hyposmia without nasal } \\
\text { obstruction nor } \\
\text { rhinorrhea }\end{array}$ & $23(12 \%)$ & $40(31 \%)$ & $11(17 \%)$ & $<0.001$ & $<0.0001$ & 0.282 & 0.084 \\
\hline Hypogeusia & $26(13 \%)$ & $77(60 \%)$ & $27(43 \%)$ & $<0.001$ & $<0.001$ & $<0.001$ & 0.032 \\
\hline Persistent hypogeusia & $22 / 26(85 \%)$ & $26 / 77(34 \%)$ & $22 / 27(81 \%)$ & $<0.001$ & $<0.001$ & 0.309 & 0.002 \\
\hline
\end{tabular}

Data expressed in median (IQR) for continuous variables or $N(\%)$ for qualitative data

patients had respiratory severity criteria defined as a hypoxemia-requiring oxygen therapy, with $37 \%$ needing an oxygen therapy $\geq 31,6 \%$ needing non-invasive ventilation, and $6 \%$ who had been in intensive care unit with necessity of invasive ventilation before they were transferred to medicine departments upon clinical improvement. Four outpatients seen in the health centers showed signs of respiratory severity and were transferred to hospital after their consultation, of which 2 reported hyposmia and 3 hypogeusia.

Univariate analysis revealed that patients with hyposmia and/or hypogeusia were significantly more frequently female (55\%) and younger (46.5 years old in median) and had significantly less comorbidities than patients without hyposmia nor hypogeusia (44\% of female and 60 years old in median) (Table 3). They had had COVID-19 symptoms significantly longer (11 vs 9 days), with significantly more asthenia and headaches, but with significantly less signs of respiratory severity. In the multivariate analysis, hyposmia and/or hypogueusia were significantly more frequent in younger patients $(\mathrm{OR}=0.97[0.96-0.99], p<0.001)$, in the absence of bronchopathy $(\mathrm{OR}=0.44[0.21-0.94], p=0.034)$, of neurological disease $(0.27$ [0.08-0.95], $p=0.047)$, and of respiratory severity $(0.51[0.29-0.91], p=0.023)$. They were more frequently present in patients reporting asthenia $(\mathrm{OR}=4.83$
[2.7-8.65], $p<0.001)$ and headache $(\mathrm{OR}=1.88$ [1.11-3.19], $p=0.018)$.

\section{Discussion}

This cross-sectional study found that one-third of COVID-19 patients reported hyposmia and/or hypogeusia, which occurred significantly more frequently in non-severe outpatients. Olfactory and taste disorders were associated with absence of signs of respiratory severity and of other neurological symptoms. A previous study among 45 hospitalized COVID-19 patients found as well that anosmia was not a predictor of a severe COVID-19 manifestation, with no difference of outcome at day 15 , or by counting the worst outcome during the hospital stay defined by a rating on a 6-point ordinal scale, between patients with and without anosmia or hyposmia [7]. Moreover, as previously described [5, 6, 8], women reported hyposmia or/and hypogueusia more often, but the difference was not significant in multivariate analysis. It has already been shown that women were at lower risk of severe forms of COVID-19 and less frequently hospitalized than men $[9,10]$.

Although viral upper respiratory infections account for up to $30 \%$ of hyposmia cases [11], sensorineural viral anosmia is 
Table 3 Comparison of demographics, comorbidities, symptoms, and severity criteria between patients with hyposmia and/or hypogeusia and patients without hyposmia nor hypogeusia

\begin{tabular}{|c|c|c|c|c|c|}
\hline \multirow[b]{2}{*}{ Variables } & \multicolumn{3}{|l|}{ Univariate analysis } & \multicolumn{2}{|c|}{ Multivariate analysis } \\
\hline & $\begin{array}{l}\text { No hyposmia nor } \\
\text { hypogeusia } N=237\end{array}$ & $\begin{array}{l}\text { Hyposmia and/or } \\
\text { hypogeusia } \\
N=153\end{array}$ & $p$ value & OR $(95 \% \mathrm{CI})$ & $p$ value \\
\hline Age (years) & $60(47-75)$ & $46.5(33-56)$ & $<0.001$ & $0.97(0.96-0.99)$ & $<0.001$ \\
\hline Female & $104(44 \%)$ & $84(55 \%)$ & 0.038 & & \\
\hline HTA & $79(33 \%)$ & $32(21 \%)$ & 0.011 & & \\
\hline Diabetes & $45(19 \%)$ & $16(10 \%)$ & 0.032 & & \\
\hline Obesity & $25(11 \%)$ & $12(8 \%)$ & 0.48 & & \\
\hline Bronchopathy & $40(17 \%)$ & $12(8 \%)$ & 0.014 & $0.44(0.21-0.94)$ & 0.034 \\
\hline Cardiopathy & $37(16 \%)$ & $8(5 \%)$ & 0.002 & & \\
\hline Nephropathy & $17(7 \%)$ & $3(2 \%)$ & 0.032 & & \\
\hline Neurological diseases & $25(11 \%)$ & $3(2 \%)$ & 0.001 & $0.27(0.08-0.95)$ & 0.042 \\
\hline Cancer & $22(9 \%)$ & $4(3 \%)$ & 0.011 & & \\
\hline Hemopathy & $14(6 \%)$ & $2(1 \%)$ & 0.034 & & \\
\hline Graft & $7(3 \%)$ & $2(1 \%)$ & 0.49 & & \\
\hline $\begin{array}{l}\text { Other } \\
\text { immunodepressio- } \\
n^{*}\end{array}$ & $17(7 \%)$ & $7(5 \%)$ & 0.39 & & \\
\hline $\begin{array}{l}\text { Time since onset of } \\
\text { first symptom } \\
\text { (days) }\end{array}$ & $9(5-13)$ & $11(8-15)$ & 0.001 & & \\
\hline Asthenia & $132(56 \%)$ & $133(87 \%)$ & $<0.001$ & $4.83(2.7-8.65)$ & $<0.001$ \\
\hline Cough & $178(75 \%)$ & $121(79 \%)$ & 0.39 & & \\
\hline Fever & $170(72 \%)$ & $106(69 \%)$ & & & \\
\hline Headache & $60(25 \%)$ & $88(58 \%)$ & $<0.001$ & $1.88(1.11-3.19)$ & 0.018 \\
\hline $\begin{array}{l}\text { Diarrhea and/or } \\
\text { vomiting }\end{array}$ & $69(29 \%)$ & $51(33 \%)$ & 0.43 & & \\
\hline Dyspnea & $119(50 \%)$ & $56(37 \%)$ & 0.009 & & \\
\hline $\begin{array}{l}\text { Neurological } \\
\text { manifestations }\end{array}$ & $18(8 \%)$ & $14(9 \%)$ & 0.58 & & \\
\hline $\begin{array}{l}\text { Signs of respiratory } \\
\text { severity }\end{array}$ & $101(43 \%)$ & $28(18 \%)$ & $<0.001$ & $0.51(0.29-0.91)$ & 0.023 \\
\hline Oxygen therapy $\geq 31$ & $60(25 \%)$ & $15(10 \%)$ & 0.0002 & & \\
\hline $\begin{array}{l}\text { Non-invasive } \\
\text { ventilation }\end{array}$ & $12(5 \%)$ & $0(0 \%)$ & 0.004 & & \\
\hline Invasive ventilation & $8(3 \%)$ & $3(2 \%)$ & 0.54 & & \\
\hline
\end{tabular}

${ }^{*}$ HIV, autoimmune disease, inflammatory disease, sickle cell anemia. Data expressed in median (IQR) for continuous variables or $N(\%)$ for qualitative data rare in the absence of rhinosinusitis and oedema in the nasal vault or olfactory cleft, with one to two new-onset patient each year in general ENT practice [12]. However, previous reports highlighted that hyposmia in COVID-19 patients occurs often suddenly, in the absence of nasal obstruction. In our series, $57 \%$ of patients who reported hyposmia did not have nasal obstruction or rhinorrhea (19\% of all patients). In a European, multicenter study on 417 mild-to-moderate hospitalized or outpatient COVID-19-confirmed patients, 76 patients (18.2\%) did not suffer from rhinorrhea or nasal obstruction, of which $79.7 \%$ reported nonetheless sudden smell disorders (14\% of all patients) [5]. In a French study on 252 patients tested for SARS-CoV-2, of whom 68 were positive, the combination of hypogeusia and hyposmia in patients with no medical history of ENT disorders had a sensitivity of $42 \%$ (95\% CI 27-58) and a specificity of 95\% (95\% CI 90-98) for COVID19 diagnosis [13]. Even though other respiratory viruses are known to cause post-viral olfactory dysfunction, the sudden onset of hyposmia and hypogeusia in a patient seems therefore quite specific for COVID-19 in the current context.

As previously described [5, 8], timing of olfactory and taste disorders onset in respect of other symptoms seems rather variable, predominantly at the same time or after the other symptoms in our series. Hyposmia and hypogeusia may go 
unnoticed early in their development. The question of recovery of olfactory and gustatory function is an important issue that remains unsolved. In our series, among patients with an infection onset $>14$ days before interview and initial hyposmia or hypogeusia, $34 \%$ of patients still had persistent hyposmia and $29 \%$ persistent hypogeusia. In the study by Lechien et al., $56 \%$ of patients with an infection onset $>$ 14 days before and a resolution of general COVID-19 symptoms still had persistent olfactory dysfunction [5].

This sudden loss of smell without nasal obstruction and its higher frequency in non-severe patients raises questions about the underlying pathogenetic mechanism of hyposmia in COVID-19. Indeed, as already described with other coronaviruses (CoVs) causing post-viral olfactory loss (PVOL) [14], local nasal inflammation resulting in mucosal edema and nasal obstruction do not appear to be the only etiological factors underlying olfactory dysfunction in COVID-19. An involvement of the central nervous system (CNS) has been suspected, as it is known that CoVs can invade it inducing neurological diseases [15], and SARS-CoV particles have been detected in cerebrospinal fluid and in the brain $[16,17]$. Likewise, a growing body of evidence shows that SARS-CoV-2 has a neurotropism, with $36.4 \%$ of 214 COVID-19-confirmed patients hospitalized in Wuhan hospitals, China, showing neurological manifestations, including $25 \%$ with central neurological manifestations, such as acute cerebrovascular disease, impaired consciousness, ataxia and epilepsy, and $9 \%$ with peripheral neurological signs, such as hypogeusia (5.6\%) and hyposmia (5.1\%) [18]. An increasing number of cases of various COVID-19-related neurological diseases are now being reported, such as meningitis, encephalitis, and Guillain-Barré syndrome [19].

The volume of the olfactory bulb (OB) is known to be decreased in patients with PVOL and is inversely related to the duration of olfactory loss [20]. Four reports of the findings on nasal cavity and brain magnetic resonance imaging (MRI) in patients with COVID-19 and sudden olfactory loss found various results: no abnormality [21], bilateral obstructive inflammation of olfactory clefts without anomalies of the OB and tracts [22], bilateral transient OB edema [23], and transient cortical hyperintensity in the right gyrus rectus and in the OB [24]. Furthermore, a report of a decreased metabolic activity in the orbitofrontal cortex on a ${ }^{18-}$ FDG PET/CT scan of a patient with COVID-19-related anosmia suggested that there could be an impaired neural activity in olfactory pathways despite normal morphology [25].

Peripherally located olfactory dendrites within receptor cells that connect to the OB may provide SARS-CoV-2 a retrograde trans-synaptic route for neuroinvasion. SARS$\mathrm{CoV}$ have demonstrated in a mice model a neuroinvasion through the olfactory bulb via transneural route [26]. Moreover, angiotensin converting enzyme 2 receptor (ACE2), which is used by SARS-CoV-2 to bind and penetrate into the human host cells, is widely expressed on the epithelial cells of the oral and nasal mucosa [27]. Therefore, there could be a direct contact and interaction with a possible cytopathic effect of SARS-CoV-2 on ACE2-expressing neurosensory receptor cells [28]. Given the prevalence of hyposmia in COVID-19 and the higher frequency in non-severe patients that appears in our study, damage to olfactory receptors in the epithelium of the nasal mucosa or in the olfactory bulbs seems more likely than central cortical involvement [25].

This study has some limitations. First, the comparison of the 3 groups of patients should be interpreted with caution as the patients were not interviewed at the same stage of the disease progression. Hospitalized patients may have been less aware about smell or taste changes due to their age, general condition, other symptoms, and context of hospitalization. Primary care outpatients, who reported fewer hyposmia and hypogeusia than the hospital outpatients, were seen sooner in the disease evolution, and some of them may not have had COVID-19 as they were not all tested. On the contrary, hospital outpatients were interviewed later in the evolution of the disease, were all COVID-19 confirmed, and were perhaps more attentive to their symptoms, being confined to the home at the time of the interview (they also reported more asthenia and headaches than other patients). In addition, the inpatient and outpatient groups may not correspond exactly to severe and non-severe groups, as some patients were hospitalized due to heavy comorbidities or difficult home support, and some ambulatory patients may have developed signs of severity afterwards. Second, given the diffusivity of the disease and the emergency context, we did not perform specific examinations for olfactory and gustatory functions, such as a more structured questionnaire associated with validated olfactory tests or electrophysiological methods. However, we distinguished patients who reported hyposmia together with nasal obstruction or rhinorrhea, reflecting an inflammation of the nasal mucosa, which could be a different mechanism than that of patients with sudden loss of smell without nasal complaints. We also did not specify if the four taste modalities (bitter, sour, sweet, salty) were impaired in themselves in patients who reported taste disorders; therefore, there could be a confusion related to the retro-olfaction. However, nearly $20 \%$ of our patients with hypogeusia did not report associated olfactory disorder, suggesting that retroolfaction impairment is not the only mechanism underlying taste disorders in COVID-19. Third, the lack of follow-up of our patients limits us from inquiring into the recovery time of olfactory and gustatory functions, and, therefore, the rate of permanent hyposmia or hypogeusia.

In conclusion, hyposmia and hypogeusia are frequent COVID-19 symptoms, more common than what was initially reported in China, especially in younger, non-severe patients. These symptoms should alert physicians when seeing a patient with influenza-like illness in the current epidemiological context and might be a useful tool for initial diagnostic work-up in patients with suspected COVID-19. Future epidemiological, 
clinical, and basic science studies must elucidate the mechanisms underlying the development of these symptoms, its predictive value of disease severity, the frequency of persistence overtime, and their long-term consequences.

Acknowledgments We thank the clinical research team (Aida ZarhrateGhoul, Soumeya Hammal, Yasmine Dudoit, Sandrine Ndinga-Mondze); Marcel Trigon Municipal University Health Center, Arcueil, France; Pierre Rouques Medical Health Center, Villejuif, France; and the patients who participated in this study. We also appreciate the final editing assistance provided by Amy Whereat, a professional medical writer.

\section{Compliance with ethical standards}

The research protocol was reviewed and approved by the Ethics Committee of the Sorbonne University (CER-SU) under the Institutional Review Board $\mathrm{N}^{\circ}$ 2020-CER-2020-8. According to French law (n ${ }^{\circ} 78-17$ of 6 January 1978 on computers, files, and liberties), this study has been registered with the CNIL (French National Agency Regulating Data Protection) and was conducted in compliance with the reference methodology 004

Conflict of interest The authors declare that they have no conflicts of interest.

\section{References}

1. Iacobucci G (2020) Sixty seconds on ... anosmia. BMJ 368:m1202

2. Vaira LA, Salzano G, Deiana G, De Riu G (2020) Anosmia and ageusia: common findings in COVID-19 patients. Laryngoscope

3. Loss of sense of smell as marker of COVID.pdf. Available at: https://www.entuk.org/sites/default/files/files/Loss $\% 20$ of\% 20 sense $\% 20$ of $\% 20$ smell $\% 20$ as $\% 20$ marker $\% 20$ of $\% 20$ COVID. pdf. Accessed 30 March 2020

4. Giacomelli A, Pezzati L, Conti F et al (2020) Self-reported olfactory and taste disorders in SARS-CoV-2 patients: a cross-sectional study. Clin Infect Dis

5. Lechien JR, Chiesa-Estomba CM, De Siati DR, et al. Olfactory and gustatory dysfunctions as a clinical presentation of mild-tomoderate forms of the coronavirus disease (COVID-19): a multicenter European study. Eur Arch Otorhinolaryngol 2020; Available at: http://link.springer.com/10.1007/s00405-020-05965-1. Accessed 7 April 2020

6. Speth MM, Singer-Cornelius T, Obere M, Gengler I, Brockmeier SJ, Sedaghat AR (2020) Olfactory dysfunction and sinonasal symptomatology in COVID-19: prevalence, severity, timing, and associated characteristics. Otolaryngol-Head Neck Surg; Available at: https://www.ncbi.nlm.nih.gov/pmc/articles/PMC7240313/. Accessed 26 May 2020

7. Hornuss D, Lange B, Schröter N, Rieg S, Kern WV, Wagner D. Anosmia in COVID-19 patients. Clin Microbiol Infect 2020; Available at: https://www.ncbi.nlm.nih.gov/pmc/articles/ PMC7242197/. Accessed 3 June 2020

8. Spinato G, Fabbris C, Polesel J et al (2020) Alterations in smell or taste in mildly symptomatic outpatients with SARS-CoV-2 infection. JAMA 323:2089-2090

9. Guan W-J, Ni Z-Y, Hu Y et al (2020) Clinical characteristics of coronavirus disease 2019 in China. N Engl J Med

10. Onder G, Rezza G, Brusaferro S (2020) Case-fatality rate and characteristics of patients dying in relation to COVID-19 in Italy. JAMA
11. Seiden AM (2004) Postviral olfactory loss. Otolaryngol Clin 37: $1159-1166$

12. Xydakis MS, Dehgani-Mobaraki P, Holbrook EH, et al. Smell and taste dysfunction in patients with COVID-19. Lancet Infect Dis 2020;: S1473309920302930

13. Bénézit F, Le Turnier P, Declerck C et al (2020) Utility of hyposmia and hypogeusia for the diagnosis of COVID-19. Lancet Infect Dis

14. Suzuki M, Saito K, Min W-P et al (2007) Identification of viruses in patients with postviral olfactory dysfunction. Laryngoscope 117: 272-277

15. Desforges M, Le Coupanec A, Stodola JK, Meessen-Pinard M, Talbot PJ (2014) Human coronaviruses: viral and cellular factors involved in neuroinvasiveness and neuropathogenesis. Virus Res 194:145-158

16. Xu J, Zhong S, Liu J et al (2005) Detection of severe acute respiratory syndrome coronavirus in the brain: potential role of the chemokine mig in pathogenesis. Clin Infect Dis 41:1089-1096

17. Gu J, Gong E, Zhang B et al (2005) Multiple organ infection and the pathogenesis of SARS. J Exp Med 202:415-424

18. Mao L, Jin H, Wang M et al (2020) Neurologic manifestations of hospitalized patients with coronavirus disease 2019 in Wuhan, China. JAMA Neurol

19. Ellul M, Benjamin L, Singh B, et al. Neurological associations of COVID-19. SSRN Electron J 2020; Available at: https://www.ssrn. com/abstract=3589350. Accessed 4 June 2020

20. Yao L, Yi X, Pinto JM et al (2018) Olfactory cortex and olfactory bulb volume alterations in patients with post-infectious olfactory loss. Brain Imaging Behav 12:1355-1362

21. Galougahi MK, Ghorbani J, Bakhshayeshkaram M, Naeini AS, Haseli S. Olfactory bulb magnetic resonance imaging in SARSCoV-2-induced anosmia: the first report. Acad Radiol 2020; Available at: https://www.ncbi.nlm.nih.gov/pmc/articles/ PMC7151240/. Accessed 3 June 2020

22. Eliezer M, Hautefort C, Hamel A-L et al (2020) Sudden and complete olfactory loss function as a possible symptom of COVID-19. JAMA Otolaryngol- Head Neck Surg

23. Laurendon T, Radulesco T, Mugnier J et al (2020) Bilateral transient olfactory bulbs edema during COVID-19-related anosmia. Neurology. https://doi.org/10.1212/WNL.0000000000009850

24. Politi LS, Salsano E, Grimaldi M. Magnetic resonance imaging alteration of the brain in a patient with coronavirus disease 2019 (COVID-19) and anosmia. JAMA Neurol 2020; Available at: https://jamanetwork.com/journals/jamaneurology/fullarticle/ 2766765. Accessed 3 June 2020

25. Karimi-Galougahi M, Yousefi-Koma A, Bakhshayeshkaram M, Raad N, Haseli S. 18FDG PET/CT scan reveals hypoactive orbitofrontal cortex in anosmia of COVID-19. Acad Radiol 2020; Available at: https://www.ncbi.nlm.nih.gov/pmc/articles/ PMC7196385/. Accessed 4 June 2020

26. Netland J, Meyerholz DK, Moore S, Cassell M, Perlman S (2008) Severe acute respiratory syndrome coronavirus infection causes neuronal death in the absence of encephalitis in mice transgenic for human ACE2. J Virol 82:7264-7275

27. Xu H, Zhong L, Deng J et al (2020) High expression of ACE2 receptor of 2019-nCoV on the epithelial cells of oral mucosa. Int J Oral Sci 12:8

28. Finsterer J, Stollberger C. Causes of hypogeusia/hyposmia in SARS-CoV2 infected patients. J Med Virol n/a Available at: https://onlinelibrary.wiley.com/doi/abs/10.1002/jmv.25903. Accessed 3 June 2020

Publisher's note Springer Nature remains neutral with regard to jurisdictional claims in published maps and institutional affiliations. 